\title{
Causes of blindness in rural Myanmar (Burma): Mount Popa Taung-Kalat Blindness Prevention Project
}

This article was published in the following Dove Press journal:

Clinical Ophthalmology

22 July 2009

Number of times this article has been viewed

\section{Arie Y Nemet ${ }^{1}$ \\ Pinhas Nemet ${ }^{2}$ \\ Geoff Cohn ${ }^{3}$ \\ Gina Sutton \\ Gerald Sutton ${ }^{4}$ \\ Richard Rawson ${ }^{4}$ \\ 'Department of Ophthalmology, Sydney Hospital and Sydney Eye Hospital, Sydney, Australia; ${ }^{2}$ Sackler School of Medicine, Tel-Aviv University, Israel; ${ }^{3}$ Departments of Ophthalmology, University of New South Wales, Sydney, Australia; ${ }^{4}$ Department of Ophthalmology, University of Sydney, Australia}

Correspondence: Arie Y Nemet Yony Netanyahu 24, Givat Shemuel, Israel Tel +97235324387

Fax+972357048I2

Email nemet.arik@gmail.com
Purpose: This study is a review of the major causes of visual impairment (VI) and severe visual impairment/blindness (SVI/BL) in Mount Popa Taung-Kalat, a rural region in Myanmar (Burma).

Methods: A review of our clinical records of consecutive patients attending clinics was conducted. Participants of all ages $(n=650)$ of the population of Mount Popa Taung-Kalat and villages in its vicinity underwent ophthalmic interview and a detailed dilated ocular evaluation by trained Australian ophthalmologists and ophthalmic nurses. This evaluation included anterior segment examination with a slit lamp, intraocular pressure recording, and direct or indirect ophthalmoscopy. VI and SVI/BL were defined by the World Health Organization (WHO) criteria.

Results: Six hundred fifty subjects were screened, with a mean age of $49.0 \pm 20.6$ years (range, 1-99). One hundred five patients (16.2\%) were children (ages 1-18). Five hundred thirty-one eyes of the total 1,300 eyes $(39.5 \%)$ had VI/SVI/BL, and 40 eyes of the children (38.1\%) (average age $15.3 \pm 13.3$ ) had VI/SVI/BL. The leading causes of VI/SVI/BL were cataract with 288 cases $(54.2 \%)$, glaucoma with 84 cases (15.8\%), and corneal pathology with 78 cases $(14.7 \%)$. Of all the VI/SVI/BL cases, $8.4 \%$ were preventable, $81.9 \%$ were treatable, and total of $90.5 \%$ were avoidable.

Conclusions: In the current study, cataracts were the major cause of blindness and visual impairment, and most of the ophthalmic pathology causing blindness is avoidable. These results highlight the lack of basic ophthalmologist eye care and optician resources in rural regions in Myanmar.

Keywords: blindness, visual loss, cataract, Myanmar, Burma, epidemiology study

\section{Introduction}

Epidemiologic data from many Asian regions, including the Union of Myanmar remain scarce. The limited cataract survey data suggested that the prevalence of blindness in the adult population in rural regions of Myanmar may reach 90 per 1,000 persons. ${ }^{1}$ Among the 55 million population of Myanmar, 450,000-600,000 are estimated to have cataract-related blindness (Unofficial data, Mount Popa Taung-Kalat Blindness Prevention Project protocol 2006).

There are undoubtedly many in underserved areas that suffer from low vision or remain needlessly blind due to lack of access to basic eye care services. Rural regions neighboring Myanmar, and areas of northern India, have high rates of visual impairment than their urban counterparts. ${ }^{2-4}$

The burden of disability in terms of blind years represents a major social, emotional, and economic burden for the patients, the families, the communities, and the nation. 
Since 1991 ORBIS (a blindness prevention charity) has conducted flying eye hospital programs and hospital-based programs in Myanmar, in Yangon, the capital city, and in Mandalay. Over the preceding decade, some prominent international eye projects have been established in Burma. CBM, Helen Keller International (HKI), and other prominent international eye-related nongovernmental organizations (NGOs) also have projects in Burma.

Recently, the Meiktila Eye Study (MES) group have published a significant data, relating to the prevalence, causes, and risk factors of ocular disorder and visual impairment in rural villages in central Myanmar. ${ }^{5-17}$

Myanmar has its own public hygiene five-year (2001-2006) vision health care projects to train more ophthalmologists, nurses, assistants and 200 basic level sightcare staff. A global initiative for the elimination of avoidable blindness under the title "Vision 2020: The Right to Sight" was launched in 1999 by the World Health Organization (WHO) in collaboration with a number of international NGOs. ${ }^{18-20}$ "Vision 2020" in Myanmar emphasizes the prevention of cataract, glaucoma, and retina diseases, and lowers the blindness rate.

However, most ophthalmic services are mainly active in the big cities, and there are very few ophthalmologists based in more rural areas of Myanmar.

The Wachet Jivita Dhana Sangha Hospital at Sagaing and the Mount Popa Jivita Dhana Ahrawja Sangha Hospital have been the first and second sites for the training and equipping of auxiliary staff in this manner since 2002. The Mount Popa Taung-Kalat Blindness Prevention Project was founded in January 2005 aiming to give ophthalmic service for the population in the region of Mount Popa. Mount Popa is located about 31 miles south east of Bagan in central Burma (Figures 1 and 2). Most of the ophthalmologists come from Sydney, Australia.

This study reviews our ophthalmic clinical records among people from Mount Popa region, a rural region in Burma with a view to offering treatment to those with remediable causes.

\section{Methods}

A medical record was compiled for all patients examined at Mount Popa Jivita Dhana Ahrawja Sangha Hospital over a period of three weeks in January-February 2006 by three ophthalmic surgeons. Six hundred fifty consecutive patients attending clinics were recruited and examined. All of them underwent general medical and ophthalmic interview. The patients came from throughout the district

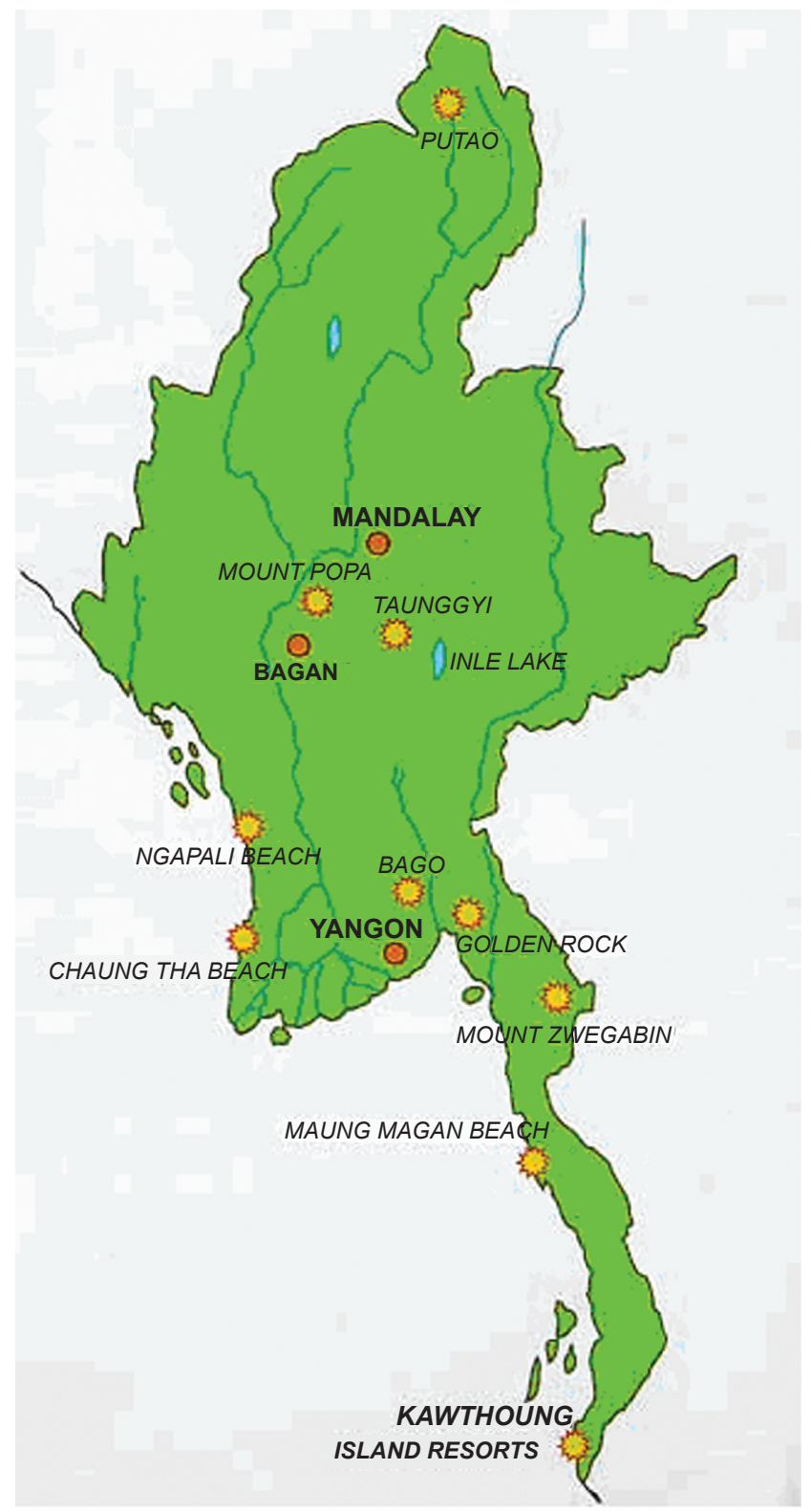

Figure I Mount Popa location in central Myanmar.

or province. The following parameters were documented: age, best-corrected visual acuity (BCVA), refraction in cases suspected to have refractive errors, full eye examination, and intraocular pressure (IOP) using a Schiötz tonometer.

BCVA and IOP measurements were performed by the local ophthalmic technicians who were trained in an informal training school established by trained Australian nurses. Mount Popa Jivita Hospital has two operating microscopes, a slit-lamp microscope, and a YAG laser which was used also for routine eye examination. The operating theatre is stocked with poly(methyl methacrylate) intraocular implants.

Visual acuity (VA) was measured using the Snellen's illiterate E chart. If the VA was less than $3 / 60$, each eye 


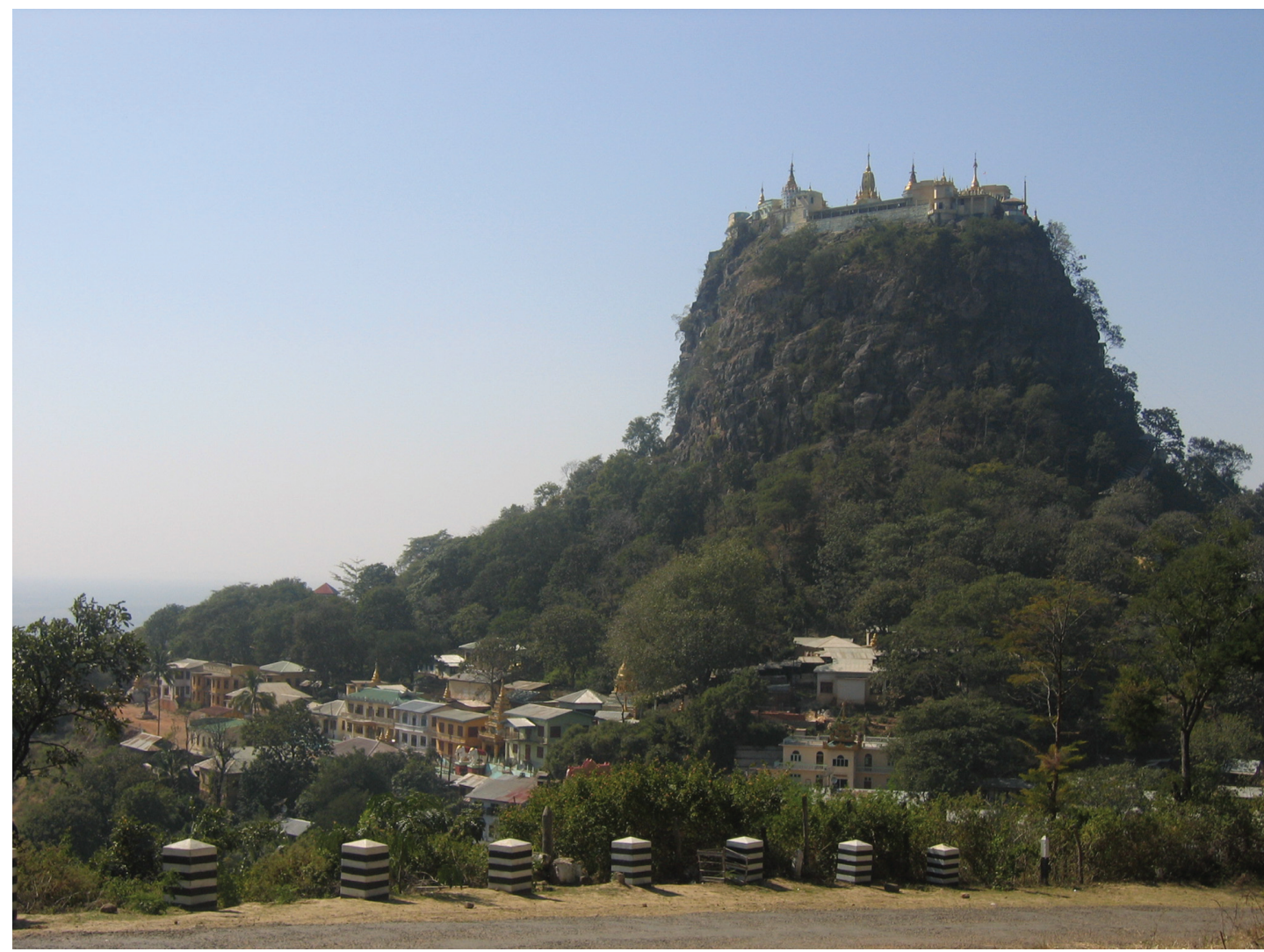

Figure 2 The summit of Mount Popa. The villages are at the bottom of the mount.

was assessed for ability to perceive light. Pinhole VA was assessed and those who improved were refracted. Anterior segment examination was performed by slit lamps. The pupils were dilated except where inappropriate (for example, phthisis bulbi, large central corneal opacity precluding view of the fundus, advanced cataract, narrow angle closure glaucoma suspected). An ophthalmologist determined the cause of visual impairment. The cause of visual loss was recorded using the anatomical and etiological classification in the form.

One definite cause of visual loss was determined in either eye. ${ }^{21,22}$ Any required therapeutic interventions were recorded and performed within two days. Spectacles were prescribed for those with refractive errors. Procedures included cataract extraction, peripheral iridotomy pterygium excision, enucleation and eyelid malposition corrective surgery. Informed consent was obtained from each patient preoperatively. Patients requiring general anesthesia were referred to eye clinics of tertiary healthcare institutions in Mandalay.

Definitions of visual loss was classified according to the WHO categories of visual impairment (Distance best-corrected visual acuity $<3 / 60$ or central visual field $<10$ degrees in the better eye). ${ }^{6}$ Accordingly, vision loss was categorized as visual impairment (VI $<6 / 18-6 / 60)$, severe visual impairment (SVI $<6 / 60-3 / 60$ ) and blindness (BL $<3 / 60-\mathrm{NLP})$.

Avoidable blindness included conditions that are amenable to primary prevention by early diagnosis or treatment (for example, by measles and rubella immunization) and those that are treatable (such as cataract removal). Data collected were entered into an IBM-compatible computer from where frequency charts and distributions were generated.

\section{Statistical analysis}

Student's $t$-test was used for continuous variables using SPSS software (v. 12; SPSS Inc. Chicago, IL, USA). Probabilities of less than $5 \%$ were considered statistically significant.

\section{Results}

In 650 patients who were examined, $105(16.2 \%)$ were children (ages 1-18). There were 334 (51.4\%) females and $316(48.6 \%)$ males. The population mean or median age was 49.0 years (range 1-99 years, standard deviation $[\mathrm{SD}] \pm 20.6)$. Fourteen children (13.3\%) were aged $1-6$ years, $45(42.9 \%)$ were aged $7-12$ years, and $46(43.8 \%)$ were aged $13-18$ years. 
Table I WHO categories of vision among the children

\begin{tabular}{|c|c|c|c|c|c|c|}
\hline WHO category & Level of vision & Right eye (n) & Left eye (n) & Total eyes n (\%) & Total $\mathrm{n}$ of patients (\%) & Children n (\%) \\
\hline I. No impairment & $6 / 6-6 / 18$ & 370 & 399 & 769 (59.2\%) & $284(43.7)$ & 65 (61.9\%) \\
\hline 2.Visual impairment & $<6 / 18-6 / 60$ & 77 & 76 & $153(11.8 \%)$ & 99 (I5.2) & $8(7.6 \%)$ \\
\hline $\begin{array}{l}\text { 3. Severe visual } \\
\text { impairment }\end{array}$ & $<6 / 60-3 / 60$ & 45 & 71 & 116 (8.9\%) & $95(14.6)$ & $7(6.7 \%)$ \\
\hline 4. Blind & $<3 / 60-$ LP & 94 & 62 & $156(12 \%)$ & $101(15.6)$ & $14(13.3 \%)$ \\
\hline 5. Blind & NLP & 65 & 41 & $106(8.2 \%)$ & $71(10.9)$ & II (I0.5\%) \\
\hline Total & & 650 & 650 & 1300 & $650(100)$ & 105 \\
\hline
\end{tabular}

Abbreviations: LP, light perception; NLP, no light perception;WHO,World Health Organization.

Five hundred thirty-one eyes of the total 1,300 eyes (40.8\%) had any visual impairment (VA $<6 / 18$ or less) and 378 eyes (29.1\%) had SVI/BL (VA of $6 / 60$ or less). Among the 105 children, 40 eyes (38.1\%) of 36 children (average age $15.3 \pm 13.3$ ) had VI/SVI/BL. Cases corrected by refraction were excluded from the VI/SVI/BL list. Two hundred sixteen patients (33.2\%) had bilateral VI/SVI/BL and four were children (3.8\%). Nineteen patients $(2.9 \%)$ had bilateral no light perception.

The distribution of the visual acuities is shown in Table 1.

\section{Anatomical causes of visual loss (Table 2) Lens}

Cataract was the single most common cause of SVI/BL with 288 cases $(54.2 \%)$ in all, and in 10 cases of children (25\%) with SVI/BL. Seven cataract cases $(2.4 \%)$ were associated with subluxation of the lens (Figure 4), four cases (1.4\%) followed trauma, and $162(56.3 \%)$ were graded as mature or hypermature cataract. Fifteen cases (5.2\%) were posterior

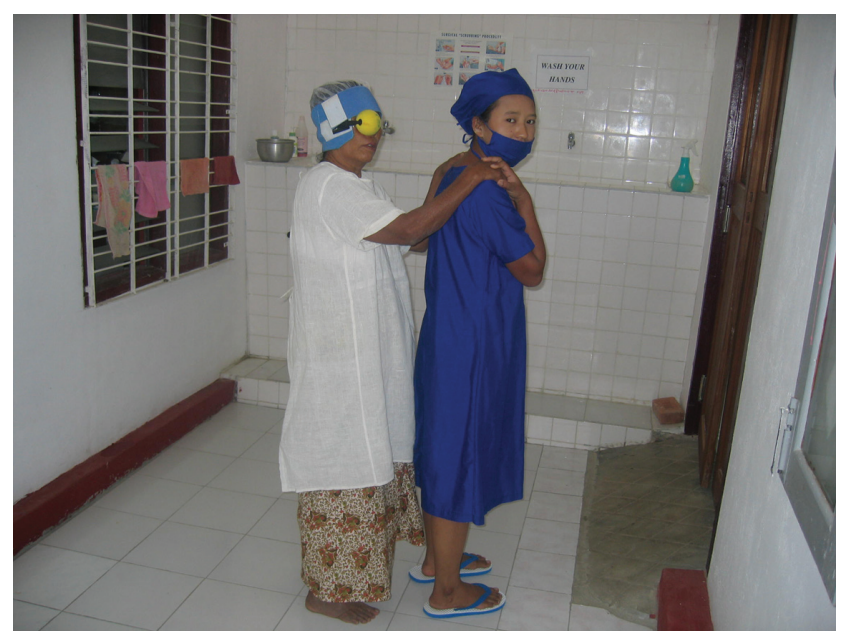

Figure $3 \mathrm{~A}$ patient with cataract is taken to theatre for cataract operation. Her right eye is prepared by retrobulbar anesthesia. capsular opacification following extracapsular cataract extraction. Seven eyes $(70 \%)$ of the children with cataract had traumatic cataract, and three (30\%) had congenital cataract.

\section{Glaucoma}

A total 123 eyes had any type of glaucoma. The average age is $58.7 \pm 19.1$ (range 9-99 years), and the average IOP was $29.8 \pm 17.1 \mathrm{~mm} / \mathrm{Hg}$. Fifteen eyes had previous trabeculectomy. VI/SVI/BL secondary to glaucoma was found in 84 eyes (15.8\%), and in four children (10\%). Primary open-angle glaucoma was found in $52(62 \%)$, and the rest had secondary glaucoma.

\section{Cornea}

Corneal scarring accounted for visual loss in 78 patients (14.7\%), and 10 of them were children (25\%). Nineteen cases (24.3\%) were congenital corneal pathology, and 59 (75.6\%) were acquired. Of the acquired cases 23 (29.5\%) were following trachoma (Figure 5), 14 (17.9\%) followed trauma (Figure 6), 10 (12.8\%) were post-corneal infections, six (7.7\%) were associated with glaucoma, four (5.1\%) were related to pterygium, and two (2.6\%) were for unknown reasons.

Table 2 Anatomical sites of abnormality leading to visual impairment

\begin{tabular}{llll}
\hline Anatomical site & $\begin{array}{l}\text { All patients } \\
\text { (n of eyes) }\end{array}$ & \% of eyes & $\begin{array}{l}\text { Ages I-I8 } \\
\text { n (\%) }\end{array}$ \\
\hline Cataract (Lens) & 288 & $54.2 \%$ & $10(25 \%)$ \\
Glaucoma & 84 & $15.8 \%$ & $4(10 \%)$ \\
Cornea & 78 & $14.7 \%$ & $10(25 \%)$ \\
Whole globe & 39 & $7.3 \%$ & II (27.5\%) \\
Retina & 25 & $4.7 \%$ & \\
Amblyopia & 10 & $1.9 \%$ & $4(10 \%)$ \\
Uvea & 4 & $0.8 \%$ & $1(2.5 \%)$ \\
Orbit/tumor & 2 & $0.4 \%$ & \\
Optic nerve & 1 & $0.2 \%$ & \\
Total & 531 & & 40 \\
\hline
\end{tabular}




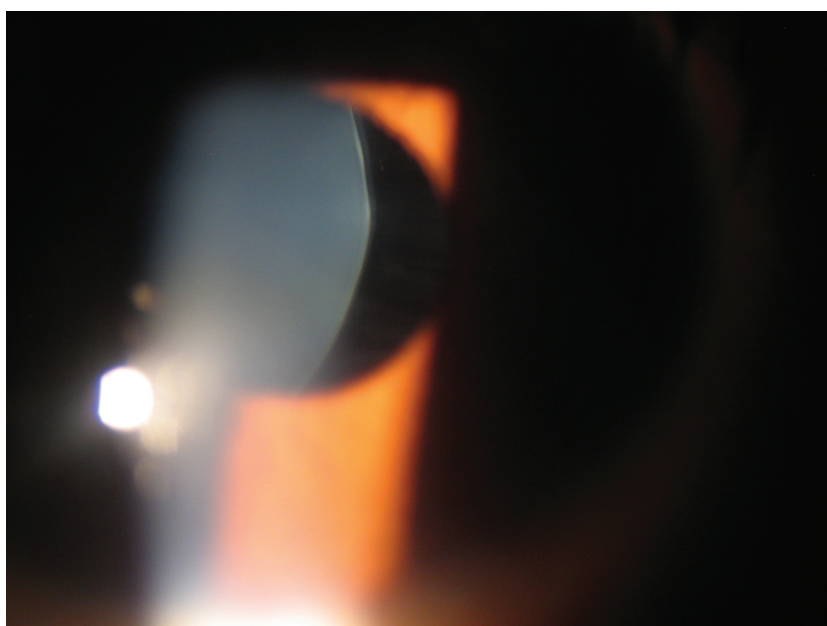

Figure 4 Bilateral lens sublaxation in a 14-year-old patient.

\section{Whole globe}

Thirty-nine patients had whole globe lesions, 11 of them in children. Twelve (30.7\%) had congenital developmental anomalies, and 27 (69.3\%) had acquired anomalies: seven with viral etiology, 11 following eye injury, four following eye infection/inflammation, and four following post-intraocular operation (cataract/glaucoma).

\section{Retina}

Twenty-five (4.7\%) eyes had VI secondary to retinal cause. Eight eyes had age-related macular degeneration, and six had a picture of retinitis pigmentosa (RP). A similar fundus presentation may be a result of Quinine toxicity which presents very similar to RP. ${ }^{23}$

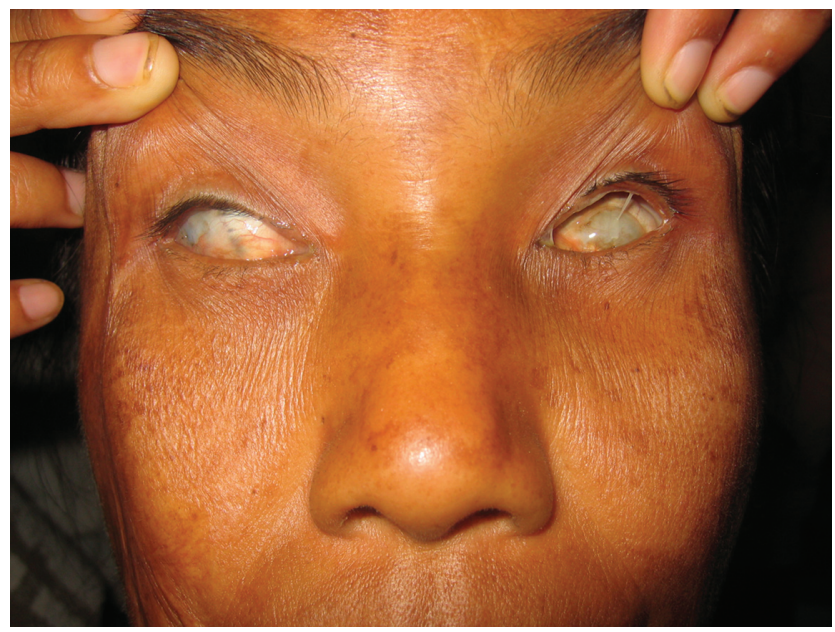

Figure 5 Bilateral severe corneal scarring and left symblepharon in a 45-year-old. The etiology is most probably infectious in origin (trachoma).

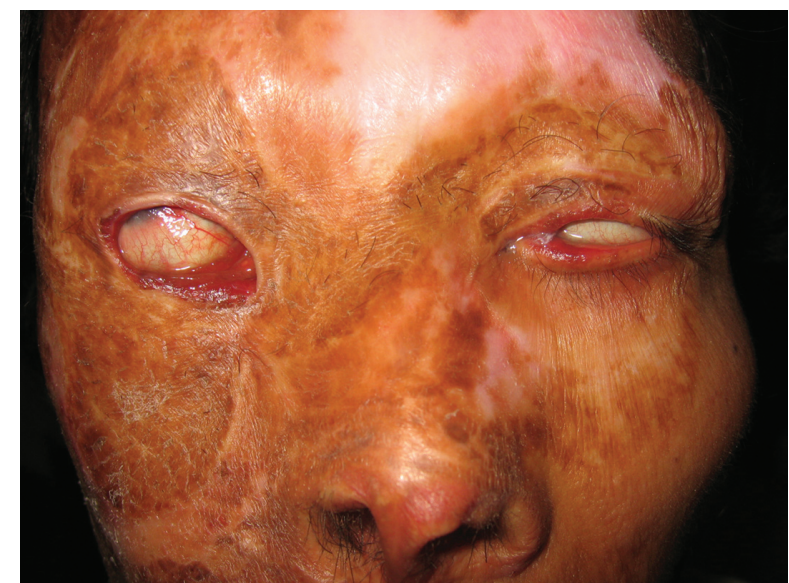

Figure $6 \mathrm{~A} 3 \mathrm{I}$-year-old man, three years after third degree face burn. He was neglected and had no medical treatment for his bilateral lagophthalmus, right missing lower lid, left lower lid ectropion which resulted with chronic conjunctival inflammation and corneal scarring.

Six had retinal changes secondary to diabetes mellitus, three had had retinal detachment, and two had retinal hemorrhage of unknown etiology.

\section{Amblyopia}

We could find only six adults (1.1\%) with VI/BL secondary to strabismic amblyopia. There were four children (3.8\%) with refractive ambyopia, two of them with dense hypermetropic aniosometropia of hand movements VA, and two with myopic anisometropia. One patient had occlusive bilateral amblyopia secondary to ptosis.

Causes of VI by age groups using etiological classification are summarized in Table 3 .

Table 4 shows the distribution of avoidable blindness. $9.4 \%$ of the SVI/BL was preventable, $81.1 \%$ was treatable, and total of $90.4 \%$ was avoidable.

\section{Discussion}

Cataract is an increasingly common cause of global blindness, particularly in developing countries with an aging population and insufficient health care resources. The profile of cataract patients in Rangoon has been described, and senile form was the commonest. However, it has not been documented in the rural areas with no modern facility available. ${ }^{24}$ Seventy percent of Myanmar's population live in rural areas and at least $25 \%$ of the population live below the UN poverty line..$^{25}$ The National health Plan recognizes the right to sight in the VISION 2020 program, one of the goals of which is to reduce the blindness rate in Myanmar to less than $0.5 \%$. Cataract removal and increasing the quality of services of cataract removal, along with development 
Table 3 Causes of visual impairment by age groups using etiological classification

\begin{tabular}{llll}
\hline & $\begin{array}{l}\text { Etiological } \\
\text { category }\end{array}$ & $\begin{array}{l}\text { All } \\
\text { (n) }\end{array}$ & $\begin{array}{l}\text { Ages } \\
\text { I-18 (n) }\end{array}$ \\
\hline Congenital & Intrauterine factor & 33 & 8 \\
& Hereditary factor & 19 & 4 \\
Developmental & Childhood factor & 22 & 6 \\
Adulthood & Cataract & $276^{*}$ & 5 \\
& Glaucoma & 84 & \\
& Trauma & 30 & 11 \\
& Trachoma & 25 & \\
& Viral/infection & 21 & 4 \\
& Unknown & 16 & 2 \\
& Uveitis & 4 & \\
& Total & 531 & 41 \\
\hline
\end{tabular}

Note: $*$ Lens opacity postcataract operation $=15$.

of the human and technical resources are key strategies in achieving that goal. ${ }^{26}$

Age-related cataract is the leading cause of blindness in Asia and has been documented in rural Myanmar., 2,427 Similar to our findings, cataract was the leading cause of both blindness and low vision, accounting for approximately two thirds of the visual impairment in the MES. The prevalence of any cataract including operated eyes was $40.39 \%$, and cataracts were strongly associated with increasing age, and are more common in those with lower education and lower body mass index. ${ }^{8}$

In our series, cataract was also the main reason for blindness. Most of the patients had mature or hypermature cataract, and considering the simple operating facility (a microscope with a simple lens system, lack of phacoemulcification) shallow anterior chambers and deep located eyes all make this operation more difficult. The prevalence of PXF in the Burmese population is greater than previously reported in other East Asian populations. Increasing age and IOP are the strongest predictors of PXF, and it is associated with cataract, occludable angles and blindness. ${ }^{7}$

Table 4 Causes of avoidable blindness among patients

\begin{tabular}{lll}
\hline & Etiology & No. of patients \\
\hline Preventable causes & Viral/Infection & $15(2.8 \%)$ \\
& Trauma & $30(5.6 \%)$ \\
Treatable causes & Cataract & $276(52.0 \%)$ \\
& Glaucoma/Buphthalmos & $84(15.8 \%)$ \\
& Corneal opacity & $75(14.1 \%)$ \\
Total avoidable & & $480(90.4 \%)$ \\
\hline
\end{tabular}

Glaucoma is recognized as the second most common cause of blindness worldwide, disproportionately affecting women and Asians, and is expected to afflict 8.4 million people by $2010 .^{27,28}$ The principal reasons for the increase in global glaucoma blindness relate to the aging population in both developed and developing countries and the inadequate detection and treatment of the disease. It is well recognized that primary angle-closure glaucoma (PACG) is generally more common in people of Asian extraction compared with other ethnicities. ${ }^{29,30}$

In the MES, glaucoma caused $17 \%$ of the nonrefractive blindness. It is in accordance with our $15.8 \%$ of visual impairment associated with glaucoma. The prevalence of glaucoma in the MES of any category in at least one eye was $4.9 \%$. The overall prevalence of PACG was $2.5 \%$ and of primary open-angle glaucoma (POAG) was $2.0 \%$. PACG accounted for $84 \%$ of all blindness due to glaucoma, with the majority due to acute angle-closure glaucoma.

PACG was associated with increasing age, axial myopia, and IOP. It had a more devastating affect on vision than primary open-angle glaucoma and was accounted for $84 \%$ of all blindness due to glaucoma, with the majority due to acute angle-closure glaucoma. ${ }^{2}$ POAG in this Burmese population was associated with increasing age, axial myopia, and IOP. ${ }^{14,16}$

The prevalence of preglaucomatous angle-closure disease (primary angle-closure suspects and peripheral anterior synechiae) in this population was $5.7 \%$ and $1.5 \%$, respectively. ${ }^{15}$ The central corneal thickness in this Burmese population was significantly associated with IOP and spherical equivalent. ${ }^{9}$

Trachoma has been a major cause of blindness for many centuries. It has led to conjunctivitis, cicatricial lid changes, and corneal opacity among populations who have been socioeconomically disadvantaged and those who have been exposed to hot, dry, and dusty environments without adequate access to water and facial hygiene. The socioeconomic and climatic conditions of central Burma, also known as a "dry zone," make it a suitable environment for high rates of active trachomatous inflammation and subsequent blindness. ${ }^{17}$

Although its prevalence in certain areas is declining, trachoma continues to account for at least 3.6\% of world blindness. ${ }^{27,31}$ At present trachoma is still the world's leading infectious cause of blindness. ${ }^{32}$ It is estimated by WHO that at present there are 146 million people worldwide with trachoma. Ten million suffer from trichiasis and need surgery to prevent corneal blindness from developing, and another 4.9 million are totally blind from trachomatous corneal scarring. ${ }^{33,34}$ 


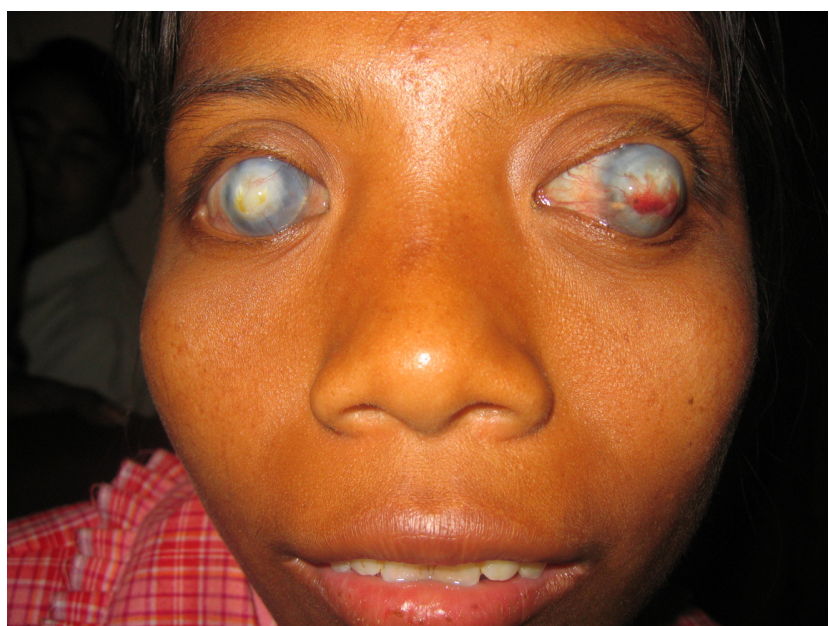

Figure 7 A 21 -year-old male with bilateral severe corneal opacity related to measles infection. His vision is bilateral with no light perception.

Trachoma in Myanmar has been known to be a problem for years. However, Myanmar has had a Trachoma Control Program (TCP) in operation since $1964 .{ }^{35}$

Surgery, antibiotics, facial cleanliness, and environmental change strategy by the involvement of the WHO not only has proven effective in reducing the prevalence of active infection and potentially blinding trachoma-related trichiasis and corneal opacity (CO), but also has been accompanied by a decline in the incidence of trachoma-related blindness and visual impairment. ${ }^{35,36}$

In the Kyaw's report from 1978, the prevalence of active disease in rural Myanmar ranged from $29.4 \%$ to $38.4 \%{ }^{36}$ The recent reported prevalence population prevalence of trachomatous trichiasis and $\mathrm{CO}$ in the MES was relatively low $(2.6 \%) .{ }^{17}$ Our result show a relatively low incidence of visual

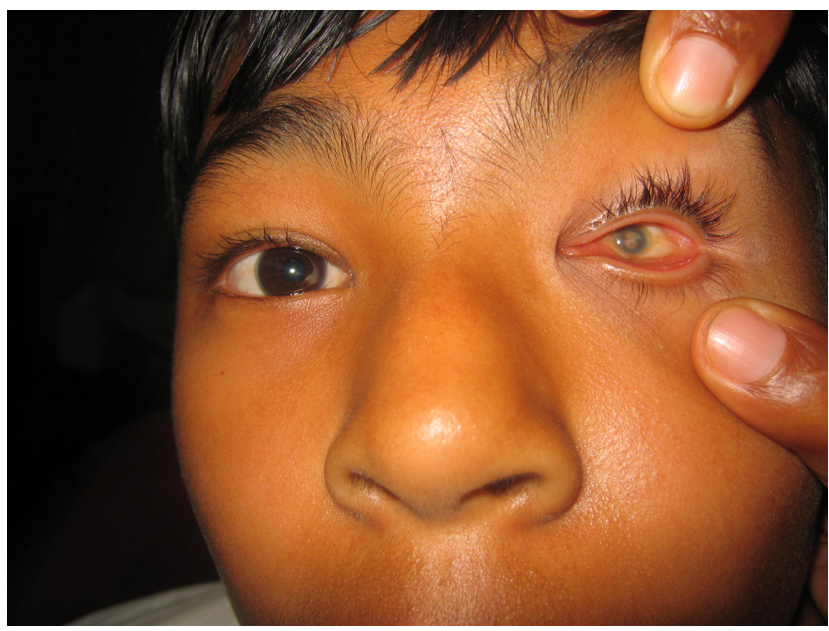

Figure 8 A I 8-year-old male with left microphthalmus related to congenital rubella infection. impairment associated with trachoma: twenty five eyes (4.7\%). We could recognize only 20 suspected cases of new trachoma and prescribed tetracycline ointment for those patients.

The significant improvement is attributed to the success of the Burma Trachoma Control Program and demonstrates the need for such a program to remain an integral part of public health care and community health services to further diminish the prevalence of this condition. However, the trachoma program in Myanmar does not cover the entire country as much of the government health service does not reach into the ethnic-held areas of Myanmar.

Corneal disease, notably trauma and infection in developing countries has only recently been recognized as a "silent epidemic". ${ }^{37}$ In 1992, Thylefors drew attention to the fact that trauma is often the most important cause of unilateral loss of vision in developing countries and that up to $5 \%$ of all bilateral blindness is a direct result of trauma. ${ }^{38}$ Findings suggest that corneal ulceration may be much more common in developing countries than previously recognized, usually associated with agricultural work and that epidemics may currently be occurring on a global scale. ${ }^{39}$ Most of the population in Myanmar are farmers working the field with primitive instrumentation and no awareness of protection. Twenty-seven of the screened patients $(5.1 \%)$, had trauma responsible for varying degrees of visual loss. These problems call for respectively prevention and early treatment. Auxiliaries moving through communities can be an effective first line of defense.

Measles can also precipitate severe vitamin A deficiency, resulting in increased systemic morbidity, mortality, corneal ulceration, and blindness.

Vitamin A deficiency remains an important cause of ocular morbidity among patients with chronic liver disease and lipid malabsorption, and is a major cause of blindness in developing countries children who receive vitamin $\mathrm{A}$ supplements to protect their eyes are also less susceptible to diarrhea and measles. ${ }^{40}$

In the MES, age-related macular degeneration was responsible for one case of bilateral blindness. It is relatively uncommon in this population, a finding consistent with other studies in developing regions, similar to our study findings. ${ }^{2,41}$

The prevalence of pterygium in central Myanmar in the MES was high: in either eye, it was $19.6 \%$ and of bilateral pterygium $8.0 \%$. The risk of developing this condition increases with outdoor occupation. Pterygium in this population is associated with $0.4 \%$ of binocular visual impairment and $1.0 \%$ of visual impairment in a least one eye. ${ }^{13}$ 


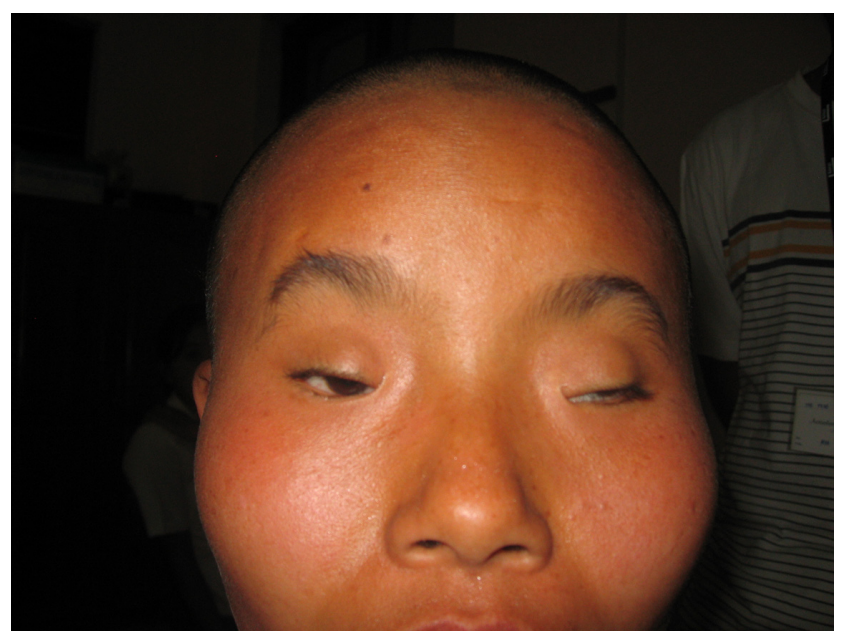

Figure 9 A 17-year-old woman with isolated blepharophimosis syndrome. She developed occlusive bilateral amblyopia of 6/18 in both eyes. We operated on both eyes (levator resection) to open her visual axis.

We did not consider refractive error as a cause for VI, unless it was not correctable.

In the MES, uncorrected refractive error caused $28.6 \%$ of the presenting blindness. Spectacles are not available in the Mount Popa region and they carry socially undesirable connotations. Community programs are needed that can detect uncorrected refractive error, can educate villagers about availability and affordability, and can alter self-image agendas regarding the wearing of spectacles. ${ }^{2}$

The prevalence rates of myopia in MES were higher than those found in other Asian regions and are likely to contribute to visual impairment. The mean refractive error in the MES was 1.3 diopters (D), and the prevalence of myopia of $0.5 \mathrm{D}$ and myopia of $1.0 \mathrm{D}$ were $51.0 \%$ and $42.7 \%$, respectively. Myopia of $6.0 \mathrm{D}$ occurred in $6.5 \%$ of subjects, hypermetropia of $1.0 \mathrm{D}$ occurred in $15 \%$, and astigmatism worse than 1.0 $\mathrm{D}$ occurred in $30.6 \%$. Anisometropia of $1.0 \mathrm{D}$ or more was $35.3 \%$ of subjects and severe anisometropia of $2.0 \mathrm{D}$ or more was present in $18.9 \%$. The higher rates of myopia and anisometropia in this population was attributed to a higher incidence of cataract. ${ }^{2,10,12}$

Myopia and cataract, but not increasing age, are the potential risk factors of anisometropia in this population. ${ }^{10}$

The current study has several limitations. The study is a summary review of our clinical records, but it is not a population-based epidemiology study. The population of Myanmar is multiethnic. Since the patients came from throughout the district or provinces they could belong to different ethnics with more than one hundred minority groups in the area. As a result of the lack of common language we couldn't get a profile regarding ethnicity. It is reasonable that different ethnic groups present different ocular pathologies.

Because of logistical constraints, and the lack of more ophthalmologists, we could not make refraction available to the patients. Corrected vision was taken as pinhole vision using a multifenestrated occluder. It is likely that a subjective refraction would have improved a percentage of subjects further. As a result, a percentage of participants are likely to have been wrongly categorized with nonrefractive causes of VI. Thus, the current study overestimates the WHO grades of VI.

Using the monastery system, the surgical needs of cataract or trachoma and the laser requirements in glaucoma can be met by regional centers which are suitably equipped, provided that these services are affordable for the poor. Some strategies for the control of blindness in patients are already being implemented. Since so many cases are treatable, and some are also preventable, vision screening in schools and villages in rural regions in Myanmar are required. The challenge is to ensure that the control of blindness will be available also to the majority of the population with no access to any medical service. It seems that a lot more work should be invested in Myanmar in order to help many VI cases.

To conclude, VI is still significant in Mount Popa region. Lack of resources, cost, remoteness, lack of awareness of available treatment, fatalism, and fear of surgery are some possible explanations. Measures to reduce blindness include more skilled ophthalmologists and optometrists in this region, population education, and subsidies for those who cannot afford ophthalmic service and surgery.

\section{Disclosure}

The authors have no commercial or proprietary interest in the subject matter of this paper. AYN conceived and designed the study, performed analysis and interpretation of data; PN conceived and designed the study and revised it critically; GC drafted the paper and revised it critically for substantial intellectual content; Richard Rawson drafted the paper and revised it critically for substantial intellectual content; Kyi Linn organized the program.

\section{References}

1. Pascolini D, Mariotti SP, Pokharel GP, et al. 2002 global update of available data on visual impairment: a compilation of population-based prevalence studies. Ophthalmic Epidemiol. 2004;11:67-115.

2. Casson RJ, Newland HS, Muecke J, et al. Prevalence and causes of visual impairment in rural Myanmar: the Meiktila Eye Study. Ophthalmology. 2007;114:2302-2308. 
3. Thulasiraj RD, Nirmalan PK, Ramakrishnan R, et al. Blindness and vision impairment in a rural south Indian population. The Aravind Comprehensive Eye Survey. Ophthalmology. 2003;110:1491-1498.

4. Wong TY, Loon SC, Saw SM. The epidemiology of age related eye diseases in Asia. Br J Ophthalmol. 2006;90:506-511.

5. Athanasiov PA, Casson RJ, Newland HS, et al. Cataract surgical coverage and self-reported barriers to cataract surgery in a rural Myanmar population. Clin Experiment Ophthalmol. 2008;36:521-525.

6. Warrier S, Wu HM, Newland HS, et al. Ocular biometry and determinants of refractive error in rural Myanmar: the Meiktila Eye Study. Br J Ophthalmol. 2008;92:1591-1594.

7. Abdul-Rahman AM, Casson RJ, Newland HS, et al. Pseudoexfoliation in a rural Burmese population: the Meiktila Eye Study. Br J Ophthalmol. 2008;92:1325-1328.

8. Athanasiov PA, Casson RJ, Sullivan T, et al. Cataract in rural Myanmar: prevalence and risk factors from the Meiktila Eye Study. Br J Ophthalmol. 2008;92:1169-1174.

9. Casson RJ, Abraham LM, Newland HS, et al. Corneal thickness and intraocular pressure in a nonglaucomatous Burmese population: the Meiktila Eye Study. Arch Ophthalmol. 2008;126:981-985.

10. Wu HM, Casson RJ, Newland HS, Muecke J, Selva D, Aung T. Anisometropia in an adult population in rural myanmar: the Meiktila Eye Study. Ophthalmic Epidemiol. 2008;15:162-166.

11. Wu HM, Gupta A, Newland HS, Selva D, Aung T, Casson RJ. Association between stature, ocular biometry and refraction in an adult population in rural Myanmar: the Meiktila eye study. Clin Experiment Ophthalmol. 2007;35:834-839.

12. Gupta A, Casson RJ, Newland HS, et al. Prevalence of refractive error in rural Myanmar: the Meiktila Eye Study. Ophthalmology. 2008;115:26-32.

13. Durkin SR, Abhary S, Newland HS, Selva D, Aung T, Casson RJ. The prevalence, severity and risk factors for pterygium in central Myanmar: the Meiktila Eye Study. Br J Ophthalmol. 2008;92(1):25-29.

14. Casson RJ, Gupta A, Newland HS, et al. Risk factors for primary openangle glaucoma in a Burmese population: the Meiktila Eye Study. Clin Experiment Ophthalmol. 2007;35(8):739-744.

15. Casson RJ, Newland HS, Muecke J, et al. Gonioscopy findings and prevalence of occludable angles in a Burmese population: the Meiktila Eye Study. Br J Ophthalmol. 2007;91:856-859.

16. Casson RJ, Newland HS, Muecke J, et al. Prevalence of glaucoma in rural Myanmar: the Meiktila Eye Study. Br J Ophthalmol. 2007;91:710-714.

17. Durkin SR, Casson RJ, Newland HS, et al. Prevalence of trachomarelated trichiasis and corneal opacity in rural Myanmar: the Meiktila Eye Study. Ophthalmology. 2007;114(5):e7-e11.

18. Pararajasegaram R. VISION 2020 - The Right to Sight: from strategies to action. Am J Ophthalmol. 1999;128:359-360.

19. World Health Organization. Programme for the Prevention of Blindness and Deafness. Global Initiative for the Elimination of Avoidable Blindness. Geneva, Switzerland: WHO; 1997.

20. Thylefors B. A global initiative for the elimination of avoidable blindness. Am J Ophthalmol. 1998;125:90-93.

21. Buch H, Vinding T, Nielsen NV. Prevalence and causes of visual impairment according to World Health Organization and United States criteria in an aged, urban Scandinavian population, The Copenhagen City Eye Study. Ophthalmology. 2001;108:2347-2357.

Clinical Ophthalmology

\section{Publish your work in this journal}

Clinical Ophthalmology is an international, peer-reviewed journal covering all subspecialties within ophthalmology. Key topics include: Optometry; Visual science; Pharmacology and drug therapy in eye diseases; Basic Sciences; Primary and Secondary eye care; Patient Safety and Quality of Care Improvements. This journal is indexed on
22. Fotouhi A, Hashemi H, Mohammad K, Jalali KH; Tehran Eye Study. The prevalence and causes of visual impairment in Tehran: the Tehran Eye Study. Br J Ophthalmol. 2004;88:740-745.

23. Handelman HL, Robertson JE, We Leber RG, Meyer SM. Retinal toxicity of therapeutic agents. Cutan Ocul Toxicol. 1983;2:131-152.

24. Le-Le-Win, Thein-Hlang, San-Shwe, Than-Htun-Oo, Ko-Ko-Tin. Profile of cataract patients in the Eye, Ear, Nose and Throat Hospital, Rangoon. Trop Doct. 1989;19:189-190.

25. Ministry of Foreign Affairs, Myanmar. Statement given by Prime Minister at the 9th ASEAN Ministerial Meeting on theEnvironment. December 17, 2003. Accessed on June 10, 2009. Available from: http://www.mofa.gov.mm/news/march06_thursday_message.html.

26. James H. Governance and civil society in Myanmar. 2005; London, UK: Routledge; 2005. p. 74.

27. Resnikoff S, Pascolini D, Etya'ale D, et al. Global data on visual impairment in the year 2002. Bull World Health Organ. 2004;82:844-851.

28. Quigley HA, Broman AT. The number of people with glaucoma worldwide in 2010 and 2020. Br J Ophthalmol. 2006;90:262-267.

29. Salmon JF, Mermoud A, Ivey A, et al. The prevalence of primary angle closure glaucoma and open angle glaucoma in Mamre, Western Cape, South Africa. Arch Ophthalmol. 1993;111:1263-1269.

30. Bourne RR, Sorensen KE, Klauber A, et al. Glaucoma in East Greenlandic Inuit - a population survey in Ittoqqortoormiit (Scoresbysund). Acta Ophthalmol Scand. 2001;79:462-467.

31. West SK. Trachoma: new assault on an ancient disease. Prog Retin Eye Res. 2004;23:381-401.

32. Taylor KI, Taylor HR. Distribution of azithromycin for the treatment of trachoma. Br J Ophthalmol. 1999;83:134-135.

33. Lim AS. Mass blindness has shifted from infection (onchocerciasis, trachoma, corneal ulcers) to cataract. Ophthalmologica. 1997;211:270.

34. World Health Organization. Future approaches to trachoma control report of a global scientific meeting, Geneva, 17-20 June 1996. Geneva, Switerland: World Health Organization; 1997. Unpublished document WHO/PBL/96.56.

35. Evans TG, Ranson MK, Kyaw TA, Ko CK. Cost effectiveness and cost utility of preventing trachomatous visual impairment: lessons from 30 years of trachoma control in Burma. Br J Ophthalmol. 1996;80:880-889.

36. Kyaw TA, Nyunt T, Sundaresan TK, Tarizzo ML. Control of trachoma and prevention of blindness in rural communities in Burma. Bull World Health Organ. 1978;56:945-955.

37. Whitcher JP, Srinivasan M. Corneal ulceration in the developing world - a silent epidemic. Br J Ophthalmol. 1997;81:622-623.

38. Thylefors B. Epidemiological patterns of ocular trauma. Aus $N Z J$ Ophthalmol. 1992;20:95-98.

39. Whitcher JP, Srinivasan M, Upadhyay MP. Corneal blindness: a global perspective. Bull World Health Organ. 2001;79(3):214-221.

40. Sommer A. Vitamin A deficiency and clinical disease: an historical overview. J Nutr. 2008;138:1835-1839.

41. Saw SM, Husain R, Gazzard GM, et al. Causes of low vision and blindness in rural Indonesia. Br J Ophthalmol. 2003;87:1075-1078.

PubMed Central and CAS, and is the official journal of The Society of Clinical Ophthalmology (SCO). The manuscript management system is completely online and includes a very quick and fair peer-review system, which is all easy to use. Visit http://www.dovepress.com/ testimonials.php to read real quotes from published authors.

\section{Dovepress}

